\title{
Preparation of Rice Based ORS by Solution Method
}

\author{
Kawnish Kirtania ${ }^{* 1}$, Devjyoti Nath ${ }^{2}$ \\ ${ }^{1}$ Chemical Engineering, Bangladesh University of Engineering and Technology, Dhaka, Bangladesh \\ ${ }^{2}$ Industrial Systems Engineering, University of Regina, Saskatchewan, Canada
}

Received 25 August 2009; received in revised form 11 November 2009

\begin{abstract}
A new method has been established to make rice based ORS through absorption of salts in rice by soaking the rice in the solution of salts. The soaked rice was dried, fried, powdered and packaged. The rice powder thus prepared when mixed with water in the desired proportion, the suspensions contain $\mathrm{Na}^{+}, \mathrm{K}^{+}$and $\mathrm{Cl}^{-}$ as prescribed. The process is named 'solution method' according to the preparation procedure.
\end{abstract}

Keywords: Diarrhoea, Rice-based ORS, Absorption, Solution method

DOI:10.3329/cerb.v13i2.3132

\section{Introduction}

The World Health Organization (WHO) terms passing of three or more loose stools in the last 24 hours as diarrhoea. This is true for infants and adults. But the attention is for the infants because still 3 million children die of diarrhoea around the world according to the report of The United Nation Children Fund (UNICEF). WHO recommends the glucose based ORS that contains the right amount of salts for the diarrhoea patients. Oral rehydration therapy (ORT) using the glucose-based Oral Rehydration Salts (ORS) solution is the preferred method for treating most children with dehydration due to diarrhoea (except those with severe dehydration) and it has been used successfully in millions of cases worldwide. In many countries glucose-ORS solution is also recommended for home treatment of children with diarrhoea after they have been treated in clinics, even when there are no signs of dehydration. Glucose-ORS solution works because glucose is rapidly absorbed by most patients with diarrhoea, and this causes salt and water also to be absorbed, thus replacing the fecal losses.

The glucose based ORS is costly for the poorer segment of the population and sometimes it may cause osmotic diarrhoea due to its high osmolarity. So producing ORS from local raw material or household material is worthwhile option.

The cereal based ORS was first prepared in 1980 and several clinical trials had been performed on ricebased ORS (R-ORS) in between 1981 and 1996. During this period, the feasibility and superiority of RORS over the glucose based ORS had been reported. Initially R-ORS faced several limitations like lack of

*Corresponding author, Email:kkdwip@che.buet.ac.bd; Ph:+8801716481451 cost effectiveness, lack of stability, shorter self life and of course, need for cooking. Then precooked rice based ORS (Pc. R-ORS) was proposed to overcome all the limitations of R-ORS. But it had also short self life and was available in twin packets and thereby costly. So the hydrolyzed R-ORS with high gluco-polymers, a kind of precooked R-ORS, was proposed. It was available in single packet. But it has the discrepancies of high osmolarity which can cause osmotic diarrhoea. Then somehow, all the variations of R-ORS were found to be inferior to the glucose based ORS. To overcome these discrepancies, in 1993, Roy [1] had developed a precooked rice based ORS which had low osmolarity and a shelf life of 6-8 months. After 3 years of its development, an extensive study was made over its performance by putting it to a clinical trial in International Centre for Diarrhoeal Disease Research, Bangladesh (ICDDR,B) for three months in 1996 by Bari [2]. In 2000, Sonia and Chinu [3] worked on qualitative assurance of rice based ORS.

The outcomes of this clinical trial are listed below [2]:

- Pc. R-ORS with low glucose polymers is more efficacious than glucose based ORS in respect of more recovery rate by day 3 , shorter duration of diarrhea, less ORS solution use, less stool output and better rehydration.

- Normal feeding and early feeding does not interfere the efficacy of Pc. R-ORS with low glucose polymers and glucose based ORS.

- Pc. R-ORS with low glucose polymers has a good packet life and low osmolarity.

- It does not need cooking.

From the above results, it is obvious that this Pc. RORS is better than glucose based ORS in every aspect. It also encourages the rice salt solution at home in case (C) Bangladesh Uni. of Engg. $\mathcal{E}$ Tech. 
of the scarcity of packet ORS. The cost of the Pc. RORS depends on the price of rice. However, a suitable and proper manufacturing process to produce Pc. RORS on a large scale will reduce its cost.

Combining the two substances - fried rice powder and salts into one single mixture in an efficient way and maintaining its quality are the challenges for developing a manufacturing process to produce Pc. RORS at affordable price. The solution method for Pc. R-ORS aims at achieving above objectives.

\section{Mechanism and Requirements of Pc. R-ORS}

The advantage of using rice-based ORS is that glucose is slowly released. It results no accumulation across the cells and promotes sodium absorption. Because of its relatively large polymeric structure hyperosmolarity may cause but amino-acid and peptides liberated from digestion of rice, proteins may further enhance sodium absorption.

Polysaccharides and legumes (mainly amylopectin and amylose) are hydrolysed by pancreatic juice and saliva into short chain glucose-polymers. These are hydrolysed by mucosal glucosides into glucose for absorption. So, a larger amount of rice powder $80 \mathrm{~g} / 1$, in a ORS formulation confirmed that it is highly absorption efficient than glucose-ORS [1].

The use of synthetic-amino-acids and peptides is based on evidence that they are capable of promoting water and salt absorption by the mechanism that are distinct from glucose. This provides an additional benefit.

Bari [2] reported that further enhancement of the absorption of sodium and water from the small intestine through the water-soluble organic solute-linked transport, without imposing an osmotic penalty due to unabsorbed organic components can be possible by the use of :

1. Suitable polymers (polysaccharides, proteins).

2. Mixtures of rapidly absorbed organic molecules (d-hexoes, amino-acids).

3. Complex and variable mixtures of polysaccharide, proteins, amino-acids.

The mixing of ingredients shortens the duration of treatment. There is significant difference between the use of only glucose and glucose-glycine which provide significantly better results. To maximize absorption, rice-based ORS, formulation should be such that it can release: glucose $=110-160 \mathrm{mmol} / 1, \mathrm{Na}^{+}=90 \mathrm{mmol} / \mathrm{l}$, $\mathrm{K}^{+}=20 \mathrm{mmol} / \mathrm{l}$ and $\mathrm{Cl}^{-}=80 \mathrm{mmol} / \mathrm{l}$ which are close approximation of the recommendation of WHO.

\section{Experimental Work}

Different experiments were performed to collect enough data to design a feasible process. After every experiment, a decision was taken to modify the process. The following steps had been followed [4]:

1. Moisture content of rice

2. Water absorption capability of rice

3. Soaking of rice in $\mathrm{NaCl}$ solution

4. $\mathrm{NaCl}$ content in the rice powder

5. Soaking of rice in the combined solution of three salts $(\mathrm{NaCl}, \mathrm{KCL}, \mathrm{Na}-\mathrm{Citrate})$

6. Final test and reuse of solution of the salts

\subsection{Moisture Content of Rice}

This experiment was carried out to determine how much moisture rice contains at room temperature. This moisture content of rice also indicates how much drying is required to get bone dry rice. As the bone dried rice would help to use a standard concentration of salt solution for the required absorption of salts in the rice.

Figure 1 shows the plot how the weight of rice decreases as drying time progresses two samples weighing 5.111 and $100.046 \mathrm{~g}$ while the oven temperatures were maintained at about $105^{\circ} \mathrm{C}$. This temperature makes the rice pathogen and organism free.

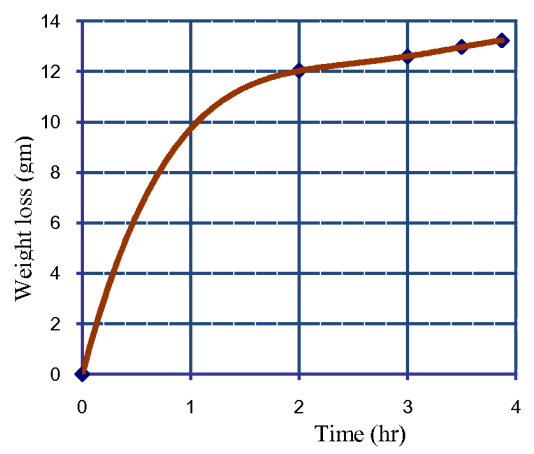

Figure 1: Plot of wt. loss per $100 \mathrm{~g}$ of rice during drying

\subsection{Water Absorption Capability of Rice}

The objective of this experiment was to determine the water absorption capability of rice. This characteristic of rice is very important for the preparation of rice based ORS by solution method. The time required for absorbing water into the rice is crucial from the view point of industrial production because this soaking time will determine the time required for preparing ORS.

From the same batch of Atop rice, 9 samples each having $50 \mathrm{~g}$ rice were used to determine water absorption characteristics of rice using different soaking time ranging from 15 minutes to 3 days.

Figure 2 shows the plot describing the water absorbing behavior of rice (non-dried). 


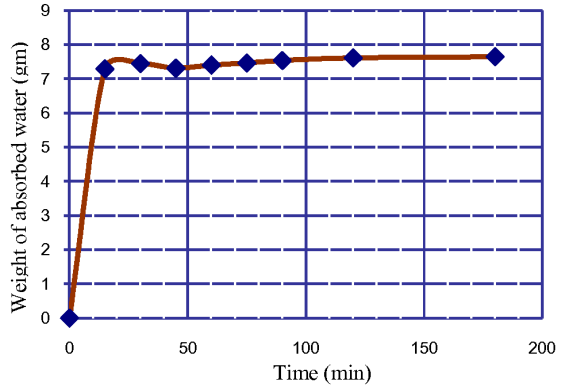

Figure 2: Plot of wt. loss per $100 \mathrm{~g}$ of rice during drying

\section{3. $\mathrm{NaCl}$ solution soaking of rice}

Before soaking rice in all types of salt solution, a single salt solution was used for the determination of salt absorption characteristics of rice in the pores. This salt retained in the rice pores would be liberated in water when reconstituted as suspension and the salt content of rice would be known. This step of experiment was important because if rice fails to pick enough salt, then the process would be infeasible.

Two samples of bone dried rice (A \& B) weighing $40 \mathrm{~g}$ each were taken. The sample 'A' was soaked in $17 \% \mathrm{NaCl}$ solution and sample 'B' was soaked in $16 \%$ $\mathrm{NaCl}$ solution. The salt solutions were made with the tap water that contains $143 \mathrm{mg} / \mathrm{l}$ of $\mathrm{Cl}^{-}$ion.

The samples were fried at $160^{\circ} \mathrm{C}$ as glucose decomposes over $170^{\circ} \mathrm{C}$. Also the rice was not turned into puffed rice. The color of rice powder was creamy and smelled like horlicks.

Table 1 shows the data on $\mathrm{NaCl}$ solution soaking behavior. The weight gained by the rice was based on the initial weight of the sample.

Table 1: Weight gain of rice with $\mathrm{NaCl}$

\begin{tabular}{lcc}
\hline & $\begin{array}{c}\text { Sample A } \\
(\mathrm{g})\end{array}$ & $\begin{array}{c}\text { Sample B } \\
(\mathrm{g})\end{array}$ \\
\hline Initial weight & 40 & 40 \\
Weight (rice + salt $)$ & 44.95 & 43.263 \\
Weight gained & 4.95 & 3.263 \\
Weight gained in \% of rice & 12.375 & 8.16 \\
\hline
\end{tabular}

\section{4. $\mathrm{NaCl}$ content in the rice powder}

The $\mathrm{NaCl}$ content in the rice powder determines whether the concentration of the solution prepared for the experiment was correct or not. If the liberated $\mathrm{NaCl}$ in the water is satisfactory in amount then the solution concentration is correct. But if the liberated $\mathrm{NaCl}$ is in excess amount then the solution concentration is to be lowered. By manipulating the concentration of the $\mathrm{NaCl}$ solution, the correct concentration of the solution is found.

Two samples (one washed and one unwashed) were soaked in $17 \%$ solution of $\mathrm{NaCl}$. Table 2 provides data on $\mathrm{NaCl}$ content of the soaked rice after frying and

\begin{tabular}{lcc}
\multicolumn{3}{l}{ Table 2: $\mathrm{NaCl}$ content of rice } \\
$\begin{array}{c}\text { Washed rice } \\
\text { sample }(\mathrm{g})\end{array}$ & $\begin{array}{c}\text { Non-washed rice } \\
\text { sample }(\mathrm{g})\end{array}$ \\
\hline Rice taken & 40 & 40 \\
$\mathrm{NaCl}$ content & 2.22 & 1.66
\end{tabular}

grinding. However, required $\mathrm{NaCl}$ content in $40 \mathrm{~g}$ rice sample is $1.75 \mathrm{~g}$. So the washed rice sample was soaked in a $16 \%$ salt solution for the next experiment. Two $10 \mathrm{~g}$ of samples from the fried powdered rice sample were mixed with water and tested in heated and non heated condition.

Table 3 shows data on $\mathrm{NaCl}$ content of rice when rice is soaked in the solution of $16 \% \mathrm{NaCl}$ at heated and normal temperature.

\begin{tabular}{ccc}
\multicolumn{3}{l}{ Table 3: $\mathrm{NaCl}$ content of rice at different conditions } \\
\hline & Heated & Non heated \\
condition & condition \\
\hline Powdered sample taken & $10 \mathrm{~g}$ & $10 \mathrm{~g}$ \\
$\mathrm{NaCl}$ content & $0.476 \mathrm{~g}$ & $0.476 \mathrm{~g}$ \\
\hline
\end{tabular}

\subsection{Soaking of rice in combined solution of three salts}

The solution method which was to be designed lied on the fact that the rice is to be soaked in the solution containing all the salts and fried rice must contain those salts in correct amounts when reconstituted in water.

Table 4 provides data on the tests performed with the combined solution of $\mathrm{NaCl}, \mathrm{KCl}$, tri-Sodium Citrate at heated and non-heated condition for fried powdered rice.

\begin{tabular}{ccc} 
Table 4: $\mathrm{Cl}^{-}$content of Pc. R-ORS at different condition \\
\hline & $\begin{array}{c}\text { Heated } \\
\text { condition }\end{array}$ & $\begin{array}{c}\text { Non heated } \\
\text { condition }\end{array}$ \\
\hline Powdered sample taken & $80 \mathrm{~g}$ & $80 \mathrm{~g}$ \\
$\mathrm{Cl}^{-}$content & 0.109 moles & 0.093 moles \\
\hline
\end{tabular}

\subsection{Final test and reuse of solution of the salts}

The economy of the process depends on how the use of different raw materials can be optimized. Rice was the raw material which got used up at its optimum quantity. But it was the solution of the salts which was to be optimized by recycling and make up. Otherwise the procedure of preparing rice based ORS by solution method would be uneconomical.

Experiments were performed for two samples by soaking bone dry rice in the same salt solution successively under heated and non heated condition. The sample size was $10 \mathrm{~g}$. Group A samples were soaked in heated and group B samples were soaked in nonheated solution successively and respectively.

Table 5 provides data on the tests performed on determining the $\mathrm{Cl}^{-}$content of the Pc. R-ORS by dissolving $10 \mathrm{~g}$ of Pc. R-ORS in $400 \mathrm{ml}$ of water. 


\begin{tabular}{cc} 
Table 5: $\mathrm{Cl}^{-}$ & content in Pc. R-ORS \\
\hline Sample & $\mathrm{Cl}^{-}$(in $80 \mathrm{~g}$ ) \\
& (mole) \\
A1 & 0.122 \\
A2 & 0.104 \\
B1 & 0.095 \\
B2 & 0.090 \\
\hline
\end{tabular}

\begin{tabular}{crr} 
Table 6: $\mathrm{Na}^{+}$and $\mathrm{K}^{+}$content in Pc. R-ORS \\
\hline Sample & $\begin{array}{r}\text { Amount of } \mathrm{Na}^{+} \\
\text {(in 1L solution) } \\
\text { (mole) }\end{array}$ & $\begin{array}{r}\text { Amount of } \mathrm{K}^{+} \\
\text {(in 1L solution) } \\
\text { (mole) }\end{array}$ \\
\hline A1 & 0.139 & 0.036 \\
A2 & 0.098 & 0.031 \\
B1 & 0.093 & 0.026 \\
B2 & 0.0918 & 0.024 \\
\hline
\end{tabular}

Table 6 provides data on the absorption of the $\mathrm{Na}^{+}$ and $\mathrm{K}^{+}$content of the rice after soaking in the solution of three salts $(\mathrm{NaCl}, \mathrm{KCl}$, tri-Sodium Citrate) in $80 \mathrm{~g}$ of rice.

\section{Discussion}

Several experiments were performed in the laboratory to evaluate every stage of the method of ORS preparation. Some experiments were performed on a trial and error basis to generate specific data for different steps of the method. The results obtained from different stepwise experiments are discussed below:

1. The amount of moisture present in the rice is a factor for absorption of salts in solution. If the moisture is properly removed before soaking in solution, more solution can be absorbed in rice. Most of the moisture (about 94\%) is removed from rice in the first 2 hours of drying. Moisture in rice is $15.23 \%$ by weight on dry basis.

2. Maximum $8 \mathrm{~g}$ of water can be absorbed by $50 \mathrm{~g}$ of rice and $90 \%$ of water is absorbed in first 20 minutes, Figure 2.

3. The same characteristic was observed during the soaking rice into $\mathrm{NaCl}$ solution. $16 \% \mathrm{NaCl}$ solution was used as the soaking medium for the bone dry rice.

4. The washed sample of rice soaked in $16 \% \mathrm{NaCl}$ solution was found to contain more than the desired amount of $\mathrm{NaCl}$ salt. But the non-washed sample can absorb less amount of salt than the washed one. So washed rice sample was preferred for this purpose.

5. Three salts - $\mathrm{NaCl}, \mathrm{KCl}$ and tri-Sodium citrate from a solution were absorbed by the rice in the desired proportion of dissociated ions. Between hot water and water at room temperature, the water at room temperature is preferred as the medium for Pc. R-ORS preparation because the salt absorbing capability of rice at an elevated temperature did not improve much.
6. The suspension of the prepared Pc. R-ORS was found to contain $0.09,0.0918$ and 0.024 moles of $\mathrm{Cl}^{-}, \mathrm{Na}^{+}$and $\mathrm{K}^{+}$ions per liter of solution respectively. The desired amount of ions in 1 liter of solution is 0.08 moles of $\mathrm{Cl}^{-}, 0.09$ moles of $\mathrm{Na}^{+}$and 0.02 moles of $\mathrm{K}^{+}$. The results look like a close match.

Based on the results, it is concluded that the method named 'solution method' is feasible. This method can also be scaled up for the large scale production.

\section{Precautions to Maintain the Quality of ORS}

1. The drying time of rice has to be enough to destroy any bacteria and spores.

2. The temperature of drying of rice should be maintained at $105^{\circ} \mathrm{C}$ for only removing water primarily but not frying the rice.

3. At $160^{\circ} \mathrm{C}$, the rice should be fried. The temperature should not be higher than this because Carbohydrates may decompose.

4. The powder should not be packed in aluminium foil as the Pc. R-ORS contains chloride ions.

5. The Pc. R-ORS powders are to be packed in airtight packets.

\section{Conclusion}

The analyses of the prepared Pc. R-ORS show that it has all the qualities of a proper ORS as per the guidelines of WHO. This new method can also become handy for a large scale production with some small modifications. A pilot study on the process will make its commercialization a success.

\section{Acknowledgement}

This work was carried out under the supervision of Dr. A. K. M. A. Quader, Professor of Chemical Engineering, BUET, Dhaka. The authors are grateful to him for his continuous support.

\section{References}

[1] Roy S, Cereal Based ORS, B. Sc. Engg. (Chemical) Thesis, Department of Chemical Engineering, Bangladesh University of Engineering and Technology, Dhaka, 1993

[2] Bari A, Efficacy of Precooked Rice-ORS and Glucose-ORS to Treat Acute Watery Diarrhoea of Children in Bangladesh, Master's thesis, Health Development Program, Faculty of Medicine, Chulalongkorn University, Bangkok, Thailand, 1996

[3] Sonia ZF and Chinu KJ, Rice Based ORS, B. Sc. Engg. (Chemical) Thesis, Department of Chemical Engineering, Bangladesh University of Engineering and Technology, Dhaka, 2000

[4] Kirtania K and Nath D, Preparation of Rice Based ORS by Solution Method, B. Sc. Engg. (Chemical) Thesis, Department of Chemical Engineering, Bangladesh University of Engineering and Technology, Dhaka, 2008 